\title{
Aspectos da teoria de Vigotski no processo de medição de grandezas físicas na universidade ${ }^{+*}$
}

Raphael Nunes Púpio Maial

Rubem Raphael dos Santos Caetano ${ }^{2}$

Universidade Federal do Rio de Janeiro - Campus Macaé

Macaé - RJ

Franciole Marinho ${ }^{3}$

Universidade Federal de São Carlos - Campus Araras

Araras - SP

\section{Resumo}

Investigamos o uso intencional de signos científicos por parte de estudantes universitários no laboratório didático de física analisando a resolução de tarefas simples de tratamento estatístico de dados num experimento hipotético de mecânica por meio de um levantamento discursivo. Interpretamos nossos resultados com base na Teoria Histórico-Cultural de Vigotski, descrevendo a forma com que estímulos externos auxiliares podem alterar o comportamento do indivíduo ao relatar, comparar, e reunir dados experimentais. Nossa abordagem naturalmente permite delinear como os signos associados às medições experimentais são gradualmente incorporados pelos indivíduos ao longo da instrução formal no ensino superior.

Palavras-chave: Ensino de Física; Medida; Análise de dados; Vigotski.

\footnotetext{
${ }^{+}$Aspects of Vygotsky's theory in the measurement process of physical quantities at the university

* Recebido: janeiro de 2016.

Aceito: julho de 2016.

${ }^{1}$ E-mail: pupio@macae.ufrj.br

2 E-mail: rcaetano@macae.ufrj.br

${ }^{3}$ E-mail: fmarinho@cca.ufscar.br
} 


\begin{abstract}
We investigated the intentional use of scientific signs by university students in Physics teaching laboratory, by analyzing the resolution of simple statistical data processing tasks in a mechanical hypothetical experiment through a written survey. We interpret our results based on Vygotsky's Historical-Cultural Theory, describing the way in which auxiliary external stimuli can alter individual's behavior to report, compare, and combine experimental data. Our approach naturally allows us to describe how the signs associated with the experimental measurements are gradually incorporated by individuals through formal instruction in Higher Education.
\end{abstract}

Keywords: Teaching of Physics; Laboratory; Measurement; Data analysis; Vygotsky.

\title{
I. Introdução
}

A linguagem científica envolve o domínio de alguns símbolos historicamente sistematizados e socialmente transmitidos que formam o meio de suporte para que grupos de pesquisa se comuniquem uns com os outros, e que junto com as práticas, as regras, os costumes, as expectativas e o comportamento desses grupos constituem a cultura científica. Em especial, àqueles envolvidos com a educação científica no laboratório de física compete a compreensão desse sistema simbólico no âmbito dos fenômenos físicos, e, portanto, a forma com que esses símbolos e suas interrelações se desenvolvem para o estudante deve ser investigada.

Diversos trabalhos foram feitos no sentido de descrever e interpretar as concepções dos estudantes sobre medição no laboratório de física, cuja revisão pode ser encontrada em Campbell et al. (2005). No âmbito do ensino pré-universitário, Lubben e Millar (apud CAMPBELL et al., 2005) desenvolveram um esquema para interpretar a progressão do entendimento de estudantes após analisar as respostas para uma série de exercícios escritos sobre vários experimentos, sendo este esquema posteriormente adaptado e aplicado no ensino superior (ALLIE et al., 1998) por meio de um questionário com perguntas sobre um experimento de mecânica. Buffler, Allie e Lubben (2001) sugeriram que o modo de raciocínio dos estudantes pode ser separado em dois extremos: o paradigma pontual e o paradigma de conjunto. No primeiro caso são encontrados os estudantes que insistem que somente uma única medida deve ser relatada numa situação experimental com incertezas aleatórias evidentes, ou seja, são incapazes de reconhecer a natureza intrínseca do processo de medição. No outro extremo estão os indivíduos que aplicam o raciocínio científico correto, i.e., que reconhecem a aleatoriedade envolvida no processo de medição, que sempre relatam um intervalo de confiança, que comparam estimativas distintas com seus respectivos intervalos de confiança, e as- 
sim por diante. Entre um e outro extremo estão aqueles cuja forma de raciocínio é uma mistura dos dois paradigmas, isto é, nem sempre fazem uso da dispersão dos dados em avaliações científicas de resultados experimentais.

Kung e Linder (2006) propuseram uma investigação no ensino superior similar às anteriores, tendo investigado uma turma no segundo ano de graduação em engenharia com a finalidade de avaliar o impacto causado por um curso de laboratório sobre a compreensão dos estudantes acerca do que é medição, e o que tarefas como relatar, comparar e combinar dados experimentais pode revelar sobre esta compreensão. Aplicaram um questionário aberto e compacto, avaliaram o uso do intervalo de confiança naquelas tarefas, e concluíram que, mesmo após um curso elaborado com o propósito de que as dificuldades encontradas pelos estudantes fossem superadas, as operações básicas de tratamento de dados experimentais não são necessariamente bem compreendidas. Observaram, ainda, que quando o enunciado de uma questão colocada para aferir o desempenho de uma determinada tarefa apresentava de forma explícita um intervalo de confiança no formato (valor central \pm incerteza), a forma de raciocinar utilizada por muitos estudantes era consideravelmente alterada em direção ao paradigma de conjunto.

Numa aproximação construtivista, Laburú, Silva e Sales (2010) examinaram as percepções de doze estudantes voluntários do ensino médio usando as mesmas tarefas de laboratório citadas acima, com a diferença de que usaram o aparato experimental assim como registros das representações semióticas do equipamento experimental (marcas de papel carbono do impacto das esferas numa folha de papel). Com entrevistas semiestruturadas, registradas em vídeo, áudio e anotações, os autores descrevem o desenrolar da interação entre cada estudante e o entrevistador quando confrontado com a coleta, o processamento e a comparação de dados experimentais. Sobre a percepção dos estudantes, relataram avanços incipientes em alguns, cuja dificuldade em reconhecer a incerteza intrínseca do procedimento de medição se apresentou como um obstáculo, ou moderados, em que a noção intuitiva de média aritmética ao processar os dados passou a ser levada em consideração. Laburú e Barros (2009) buscaram justificar a persistência do paradigma pontual fazendo uso da epistemologia de Piaget: a passagem conceitual para o paradigma de conjunto envolveria uma superação cognitiva em que "o conhecimento supera o próprio real para inserir-se no possível e ligar diretamente o possível ao necessário sem a mediação indispensável do conceito" (PIAGET, 2012, p. 48).

Embasados por implicações sociológicas associadas às diferentes perspectivas de realidade, Marineli e Pacca (2006) buscaram interpretar o motivo para a persistência da distorção do pensamento científico por parte de muitos estudantes no ensino superior nas tarefas de laboratório. Concluíram, com base na análise qualitativa de material escrito (relatórios e exercícios) produzido por estudantes brasileiros de curso de Licenciatura em Física, que as dificuldades enfrentadas pelos estudantes não se poderia justificar pela inabilidade em instrumentação e tratamento de dados, e sim por causa da forma de pensamento situacional com o qual os indivíduos percebem os objetos inseridos num contexto científico, ou melhor, devido 
à transposição das suas ideias do mundo cotidiano para a investigação empírica de fenômenos físicos. Em paralelo a esta perspectiva estão pesquisas (LURIA, 2013, 2014, 2015) acerca da influência cultural sobre a percepção, a memória, o pensamento lógico e a auto avaliação, comparando a predominância de pensamento situacional ou de pensamento abstrato de certos indivíduos, e que exemplificou alguns aspectos da teoria de Vigotski (2009) no que diz respeito à alteração produzida nos conceitos espontâneos devido ao desenvolvimento dos conceitos científicos. Nesta mesma perspectiva, Howe (1996) descreve a relação entre o ensino escolar e o desenvolvimento cognitivo através de exemplos, e relata a persistência do uso de conceitos espontâneos em tópicos científicos no ensino de ciências e de matemática.

Seguindo os apontamentos mencionados (KUNG; LINDER, 2006), no presente trabalho relatamos a aplicação do método daqueles autores e os nossos resultados para a atividade de estudantes universitários no desenrolar de tarefas que envolvem tratamento de dados experimentais. Interpretamos essa forma de organização de pensamento em termos da Teoria Histórico-Cultural de Vigotski no que diz respeito à mediação desempenhada por estímulos auxiliares. Na seção II descrevemos a mediação segundo a obra de Vigotski, processo que distingue as funções psicológicas elementares das superiores. Na seção III são descritas as turmas avaliadas, e são apresentados os métodos de coleta, análise e síntese empregados. Nossos resultados são discutidos na seção IV, e possibilitam complementar as razões sociais e culturais para as dificuldades enfrentadas pelos estudantes no laboratório de física. As considerações finais são apresentadas na seção V.

\title{
II. A mediação na teoria de Vigotski
}

Afirma Luria (2014) que Vigotski gostava de associar os termos "instrumental", "cultural" e "histórica" à psicologia quando se referia ao seu próprio trabalho. Ao usar o primeiro desses termos, Vigotski faz a distinção entre as funções ${ }^{4}$ psicológicas elementares, comum a todos os animais e determinadas diretamente a partir de estímulos externos, e as funções psicológicas superiores, exclusiva dos seres humanos e que se distinguem das anteriores por serem produtos de estímulos criados artificialmente. Luria discute esse ponto:

\begin{abstract}
Instrumental se refere à natureza basicamente mediadora de todas as funções complexas. Diferentemente dos reflexos básicos, os quais podem caracterizar-se por um processo de estímulo-resposta, as funções superiores incorporam os estímulos auxiliares, que são tipicamente produzidos pela própria pessoa. $O$ adulto não somente responde aos estímulos apresentados por um experimentador ou por seu ambiente natural, mas também altera ativamente aqueles estímulos e usa suas modificações como um instrumento de seu comportamento (LURIA, 2014, p. 26).
\end{abstract}

\footnotetext{
${ }^{4}$ Conforme destacam Pereira e Junior (2014, grifo dos autores): "É importante frisar que o termo 'função' é compatível com a noção de 'ação'. [...] tendo em vista que Vigotsky estava primeiramente interessado na análise do indivíduo em 'atividade prática' (lembrar, raciocinar, etc.)".
} 
Portanto, na medida em que um indivíduo é capaz de controlar o próprio comportamento por meio da incorporação de determinado estímulo auxiliar (signo), fica estabelecida a mediação entre o estímulo e o comportamento (resposta) por meio de uma ação reversa porque "Nesse novo processo o impulso direto para reagir é inibido, e é incorporado um estímulo auxiliar que facilita a complementação da operação por meios indiretos" (VIGOTSKI, 2007, p. 34).

A transmissão cultural e a origem na história social dos estímulos auxiliares presentes no comportamento dos indivíduos são também discutidas por Luria. O atributo cultural compreende a elaboração e a organização de tarefas com as quais a criança em desenvolvimento se defronta, assim como "os tipos de instrumentos, tanto mentais como físicos" (LURIA, 2014, p. 26) disponibilizados para a execução destas tarefas. E o atributo histórico está relacionado com a criação e o aprimoramento destes estímulos auxiliares ao longo da história social do homem. Ao realizar atividades comuns como ler, escrever, calcular, etc., o adulto reproduz um comportamento automático desenvolvido em estágios anteriores durante a aprendizagem. Foi o que Vigotski denominou de "comportamento fossilizado" (VIGOTSKI, 2007, p. 67), um termo apropriado para designar processos que exteriormente não guardam qualquer semelhança com a atividade interna ocorrida em sua gênese. Na visão sóciohistórica, "Se queremos descobrir como as habilidades culturais são desenvolvidas, devemos voltar aos primeiros estágios de sua história e descrever o caminho que elas percorreram na mente da criança" ${ }^{\circ}$ (LURIA, 2014, p. 95), justamente porque neste momento os estímulos auxiliares estão sendo experimentados e a atividade mental pode ser observada exteriormen$\mathrm{te}^{6}$.

Ao tratar especificamente da distinção entre a memória natural e a mediada, Vigotski menciona exemplos de uso de estímulos auxiliares externos:

\begin{abstract}
Mesmo essas operações relativamente simples, como atar nós e marcar um pedaço de madeira com a finalidade de auxiliares mnemônicos, modificam a estrutura psicológica do processo de memória. Elas estendem a operação de memória para além das dimensões biológicas do sistema nervoso humano, permitindo incorporar a ele estímulos artificiais, ou autogerados, que chamamos de signos (VIGOTSKI, 2007, p. 32).
\end{abstract}

Nessa perspectiva as funções psicológicas superiores extrapolam a componente genotípica, não só por se encontrar no meio exterior o estímulo, mas porque além de formar a intenção de lembrar é necessário realizar a operação inversa (i.e., alterar ativamente o estímu-

\footnotetext{
${ }^{5}$ Uma das investigações que Luria conduziu, sobre o desenvolvimento do processo de contagem, buscou entender: "Por quais estágios passa a contagem antes de se tornar abstrata e automática?" (LURIA, 2014, p. 95). Analisando as formas com que problemas simples de divisão eram resolvidos com blocos por crianças de determinadas faixas etárias, observaram uma transição na divisão de figuras de blocos concretas (tratores, sofás, etc.), para uma operação de divisão a partir de organizações espaciais abstratas (linha/coluna). Esses estágios sucessivos sugerem o início da atividade mediada, constituída por uma série de operações auxiliares.
}

${ }^{6}$ O processo de interiorização da fala na criança é um tema notório na Obra de Vigotski $(2007,2009)$. 
1o). $\mathrm{O}$ ato intencional de atar um nó num dos dedos, ou mesmo programar um alarme num aplicativo de celular, e associá-los inversamente com a lembrança no futuro de algo previamente planejado permitem que o indivíduo use um estímulo auxiliar externo para alterar seu comportamento (i.e., lembrar) por meios indiretos.

Associado a alguns conceitos de física, em particular, encontramos mnemônicos que utilizam a regra da mão direita, tais como: a direção e o sentido do momento angular, do torque realizado por uma força, da força magnética exercida sobre uma partícula carregada em movimento, dos campos elétrico e magnético de uma onda plana eletromagnética, etc. Em todos estes exemplos o pensamento abstrato com conceitos de física é mediado por estímulos auxiliares que estão relacionados a algo externo: ao ser conduzido pela mão direita é que o pensamento poderá determinar a direção e o sentido de uma determinada grandeza física vetorial, sendo necessário, para tanto, que associe para cada um dos três dedos (polegar, indicador e médio) uma determinada grandeza vetorial, isto é, que crie estímulos artificiais.

Nos dois trechos transcritos em destaque acima os autores mencionam "incorporar" no sentido de internalizar: "Chamamos de internalização a reconstrução interna de uma operação externa" (VIGOTSKI, 2007, p. 56). Entendida a operação como uma atividade (mental), dada a ação reversa característica da mediação, Vigotski considera que "A internalização de formas culturais de comportamento envolve a reconstrução da atividade psicológica tendo como base a operação com signos" (VIGOTSKI, 2007, p. 58, grifo nosso). Ou seja, aquilo que é reconstruído pelo indivíduo tem origem em comportamentos culturais, e, portanto, as funções psicológicas superiores são formadas socialmente.

Retornando ao exemplo do mnemônico estabelecido pela regra da mão direita, vemos que um determinado signo pode nunca vir a ser internalizado, como no caso de um indivíduo que sempre precise usar a própria mão com o fim de guiar o seu raciocínio. Já um indivíduo que é capaz de imaginar uma mão e de completar mentalmente todas as associações entre grandezas físicas e os correspondentes dedos da mão "imaginária" é porque utiliza modificações do instrumento fornecido a ele, e, sem dúvida, reconstruiu internamente alterações de um estímulo originalmente externo.

Nas atividades de laboratório, a incerteza é imprescindível para o correto tratamento de dados, pois os erros experimentais são os estímulos externos que dão origem ao signo mediador da percepção e do pensamento abstrato (relatar, processar, comparar, julgar, etc.). Um estudante que realiza atividades práticas de um experimento didático e prescinde da incerteza de uma medida nas suas conclusões, ou utiliza a sua percepção direta do fenômeno, relatando uma medição com um único dado concreto e não vendo razão em comparar duas medidas tal qual o comportamento descrito pelo paradigma pontual, ou utiliza a sua percepção mediada por um signo inadequado, e voluntariamente dá início a uma atividade mediada por um estímulo abstrato como, por exemplo, o valor médio. A partir daí, ocorre uma transição "para formas de comportamento qualitativamente novas" (VIGOTSKI, 2007, p. 24) porque "a relação entre as transformações dos processos perceptivos e as transformações em outras ativida- 
des intelectuais é de fundamental importância" (ibid.). O estudante capaz de relatar um intervalo de confiança e de fazer uso sistemático deste percebe indiretamente os erros de registros do aparato de medida ou mesmo aqueles devido à preparação do experimento em si como estímulos externos e os representa abstratamente por um signo: a incerteza. Ao utilizar arbitraria, voluntaria e sistematicamente a incerteza em tarefas de comparação, de julgamento, etc., a atividade do estudante estará fazendo uso do método científico tal qual o comportamento relatado pelo paradigma de conjunto.

Assim, quando a percepção opera em termos concretos, o pensamento abstrato conexo com esta não se desenvolve. Pode se desenvolver quando conduzido por um signo inadequado, ao comparar valores médios, por exemplo. Contudo, são indispensáveis percepção e pensamento mediados pela incerteza para que o tratamento de dados seja rigorosamente científico. Conforme nossa análise, e alinhado com outro trabalho (MARINELLI; PACCA, 2006), não se deve invocar a imperícia na instrumentação e no tratamento abstrato de dados como justificativa para a formação de obstáculos para a compreensão dos estudantes. A questão que levantamos como razão para a dificuldade de estudantes com o método reside na maneira com que os estímulos externos são percebidos por estudantes em sala de aula.

A perspectiva adotada neste trabalho entende o método científico como um sistema de conceitos (VIGOTSKI, 2009, p. 295) erguido a partir da produção de estímulos artificiais diversos, sendo a incerteza o estímulo artificial nuclear de todo este sistema. Portanto, justifica-se avaliar os aspectos da aprendizagem deste signo que está estreitamente relacionado com o método científico, examinando seu uso voluntário e sistemático pelos estudantes.

\section{Metodologia}

Os indivíduos analisados nessa pesquisa realizada no primeiro semestre de 2015 são estudantes universitários regularmente inscritos em disciplinas de cursos de ciências exatas no Campus Macaé da Universidade Federal do Rio de Janeiro. Parte destes estudantes (75) estava inscrita na primeira disciplina de laboratório física, a qual designamos por Turma I, e a outra parte destes (13) estavam na terceira disciplina de laboratório de física (Turma III). A maioria deles está no ciclo básico dos cursos de Engenharia, 70 da turma I e todos da turma III, sendo que os outros 5 da primeira turma estão no curso de Licenciatura em Química.

Em regra, os estudantes dos cursos de engenharia na turma I ingressaram na graduação em 2015 e estão também inscritos em disciplinas introdutórias de física teórica, cálculo diferencial e integral, e química geral, enquanto que os de Licenciatura em Química são turmas de segundo período e somente se envolvem nas disciplinas de física teórica e experimental após as disciplinas de primeiro período (dentre estas cálculo diferencial e integral). Os estudantes do ciclo básico dos cursos de engenharia na turma III já estavam há pouco mais de um ano no ensino superior, e cursaram, em regra, as duas disciplinas de laboratório de física anteriores, bem como disciplinas teóricas de cálculo, de física, de probabilidade e estatística, de álgebra linear, e prática de metrologia orientada para engenheiros. 
Nosso método de investigação consistiu em uma série de tarefas a ser resolvida na forma de um questionário de respostas abertas, cujo texto faz a narrativa de um experimento de mecânica (Fig. 1): uma pequena esfera, colocada em repouso a uma altura $h=400 \mathrm{~mm}$ numa rampa em cima de uma mesa, desce até a base da canaleta e é lançada com velocidade horizontal, aterrissando a uma distância horizontal $d$ em relação ao ponto de interseção da linha vertical do ponto de lançamento com o piso (a distância é registrada através da marcação numa folha de papel sulfite). Em seguida são apresentadas cinco medidas realizadas por um ou dois grupos hipotéticos de estudantes que devem fazer o processamento, a comparação ou o agrupamento dos seus dados experimentais ${ }^{7}$.

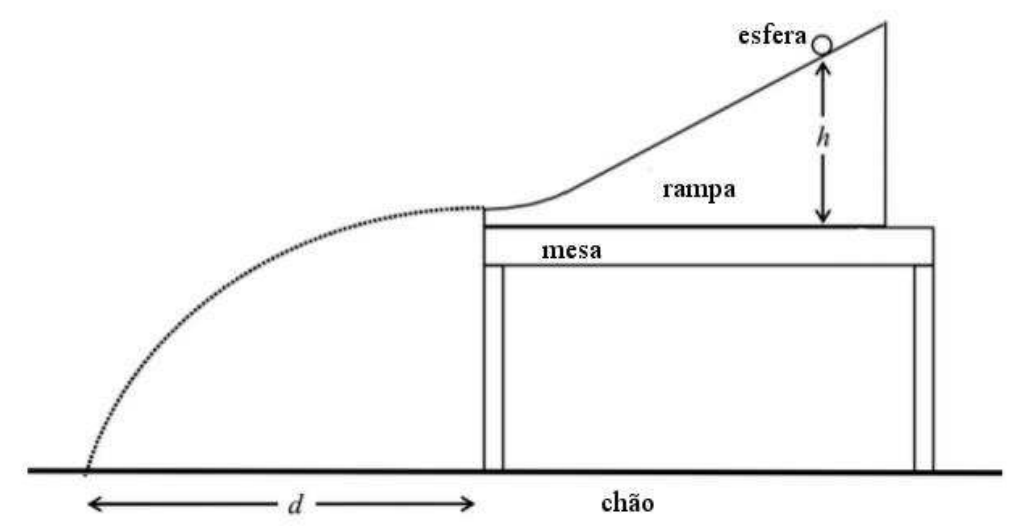

Fig. 1 - Contexto experimental do questionário de medições físicas (BUFFLER; ALLIE; LUBBEN, 2001).

Interpretar por meio de uma análise qualitativa as respostas dadas pelos indivíduos ao fazerem o tratamento de dados de grupos hipotéticos pode revelar informações à respeito dos processos psicológicos que determinaram suas respostas, ainda que nosso entendimento a cerca destes processos esteja limitado às possibilidades conferidas por um instrumento como um levantamento escrito. A análise do conteúdo das respostas buscou discernir se o estudante fez uso intencional do signo (incerteza) adequado para controlar seu comportamento e completar a tarefa, ou de algum outro signo inadequado, ou mesmo se o comportamento foi não mediado. Assim julgamos o comportamento dos estudantes em cada uma das sete tarefas resumidas na Tabela 1 no que diz respeito a determinadas operações com dados experimentais, e em seguida avaliamos quão fácil seria para ele passar do uso de um para outro signo caso um intervalo de confiança estivesse presente $(\mathrm{P})$ ou ausente $(\mathrm{A})$ no texto da tarefa.

A avaliação foi realizada independentemente por dois autores, que se reuniram posteriormente para chegar a um consenso sobre interpretações diferentes. As respostas de 42 (13) indivíduos da Turma I (III) foram compiladas numa planilha e o número de tarefas completadas com o signo inadequado em cada tarefa resultaram numa forma de comparar em valores

\footnotetext{
${ }^{7}$ O questionário (ver apêndice em Kung e Linder, 2006) foi traduzido para a língua portuguesa por um dos autores. Uma cópia da tradução pode ser obtida por meio de mensagem particular via e-mail.
} 
relativos o desempenho entre as turmas, sobretudo se a diferença entre os erros em tarefas análogas com e sem estímulo externo apresentava valores discrepantes.

A primeira tarefa consiste em como relatar cinco valores medidos por um grupo hipotético para o alcance da esfera $d(\mathrm{~mm})$ : 436, 426, 438, 426, 434. Caso o estudante tenha usado intencionalmente o intervalo de confiança, seria relatada por ele uma faixa de valores, algo como (432 \pm 5$) \mathrm{mm}$, com os valores médio e desvio padrão (ou alguma outra estimativa para a dispersão dos dados, como as medidas máxima e mínima).

Tabela 1 - Esquema resumido das tarefas, operações e estímulos externos.

\begin{tabular}{|c|c|c|}
\hline & Tarefa & Signo \\
\hline 1 & $\begin{array}{l}\text { Relatar um intervalo de confiança a par- } \\
\text { tir de cinco medições. }\end{array}$ & A \\
\hline 2 & $\begin{array}{l}\text { Avaliar a precisão de dois conjuntos de } \\
\text { cinco medidas. }\end{array}$ & A \\
\hline 3 & $\begin{array}{l}\text { Comparar dois conjuntos de cinco me- } \\
\text { didas. }\end{array}$ & A \\
\hline 4 & $\begin{array}{l}\text { Relatar apenas um intervalo de confian- } \\
\text { ça a partir de dois conjuntos de cinco } \\
\text { medidas. }\end{array}$ & A \\
\hline 5 & $\begin{array}{l}\text { Comparar dois intervalos de confiança } \\
\text { obtidos por grupos distintos. }\end{array}$ & $\mathrm{P}$ \\
\hline 6 & $\begin{array}{l}\text { Relatar apenas um intervalo de confian- } \\
\text { ça a partir de dois intervalos de confian- } \\
\text { ça. }\end{array}$ & $\mathrm{P}$ \\
\hline 7 & $\begin{array}{l}\text { Comparar dois intervalos de confiança } \\
\text { obtidos por grupos distintos. }\end{array}$ & $\mathrm{P}$ \\
\hline
\end{tabular}

A tarefa 2 informa os dados experimentais de dois grupos hipotéticos, "Grupo A - d (mm): 444, 432, 424, 440, 435 (valor médio: 435); Grupo B - d (mm): 441, 460, 410, 424, 440 (valor médio: 435)", e pede que o estudante examine a qualidade de cada conjunto de dados. Buscamos com isso averiguar qual signo o estudante utilizaria de forma independente, o valor médio ou a dispersão dos dados, ao comparar a precisão das medidas dos grupos.

Com a finalidade de avaliar a forma com que nossos estudantes comparam conjuntos de medidas, utilizamos as tarefas 3, 5 e 7 . Na primeira destas, a narrativa informa os seguintes dados: "Grupo A - d (mm): 444, 435, 424, 440, 432 (valor médio: 435); Grupo B - d (mm): 458, 438, 462, 449, 443 (valor médio: 450)". Informando os dados com seus respectivos valores médios podemos examinar com base em qual signo o indivíduo realiza a comparação, se através das dispersões, dos valores médios ou de algum outro parâmetro, isso sem qualquer menção a qual signo é o adequado. As informações contidas na tarefa 5 são "Grupo A: (432 \pm 
5) mm; Grupo B $(442 \pm 6)$ mm" e na tarefa 7 são "Grupo A: $(434 \pm 5)$ mm; Grupo B (448 \pm 5) mm", sendo colocados os desvios padrão da média (estímulos auxiliares) com o fim de observar na resposta dada se esses parâmetros numéricos alteram o comportamento do indivíduo numa operação de comparação.

Os objetivos das tarefas 4 e 6 são em última análise o mesmo da primeira, que é o de processar as informações e relatar um intervalo de valores. Contudo, os dados experimentais de dois grupos hipotéticos são descritos, todos contidos numa narrativa onde os dois grupos desejam reunir suas medidas e relatar uma única estimativa para a distância $d$. Na tarefa 4 as informações contidas no texto são os mesmos da tarefa 3, e na tarefa 6 são os mesmos que os da tarefa 5. Assim, enquanto naquela tarefa são informados os valores médios, nesta são colocados os intervalos de confiança (com um desvio padrão da média). Confrontando as respostas a essas duas tarefas, avaliamos qual signo o indivíduo usou intencionalmente para relatar a estimativa da distância $d$ em cada uma destas, isto é, se usou consistentemente o intervalo nas duas tarefas, ou, por exemplo, relatou apenas o valor médio na tarefa 4 e um intervalo de valores na tarefa 6 devido à presença do estímulo auxiliar no texto.

\section{Resultados}

Os resultados obtidos com 55 indivíduos nas turmas I e III estão resumidos nas Tabelas 2-5, sob a forma de erros absolutos e relativos com respeito ao total de indivíduos de cada turma. Na tarefa 1 é avaliada em cada estudante a formação elementar de associação entre medida e intervalo de confiança, sendo colocada para esta finalidade a questão de como um conjunto de cinco dados deve ser relatado. Observamos que nesta tarefa o número de erros em valores relativos para a turma I e para a turma III é baixo sendo um indicativo de que grande parte dos estudantes de ambas as turmas intencionalmente formaram algum vínculo associativo entre medida e intervalo de valores possíveis. Contudo, não é possível estabelecer a partir dos dados se a taxa de erros da turma III é menor que da turma I de fato ${ }^{8}$. Entretanto, a função instrumental de um signo não fica garantida apenas pela capacidade por parte do indivíduo em formar associações, conforme mostra a resposta de EI6: "Eles devem relatar quantas vezes eles fizeram o teste, mostrar a média e o seu desvio padrão das medidas obtidas. É importante também mostrar a incerteza da régua que eles usaram para que seja possível fazer uma comparação com outros experimentos do tipo". Vemos por essa resposta que o desvio padrão da média não seria levado em consideração caso fosse necessário comparar esses dados com

\footnotetext{
${ }^{8} \mathrm{O}$ teste estatístico de Fisher-Boschloo com nível de significância de 5\% foi utilizado para verificar compatibilidade ou sinalizar redução na taxa de erro tanto entre tarefas relacionadas para uma mesma turma quanto entre turmas numa mesma tarefa. O modelo empregado é o binomial (LYDERSEN et al. 2009).
} 
os de outros grupos, pois parece haver uma confusão no entendimento entre os dois métodos de estimativa de incertezas ${ }^{9}$.

Na tarefa 2, os estudantes são confrontados com conjuntos de medidas coletados por dois grupos distintos A e B, e examinamos se a incerteza foi usada como um signo para estabelecer distinção de qualidade (ou de precisão) entre os conjuntos apresentados. O baixo número de erros encontrados na turma I revela que os indivíduos são capazes de relacionar com certa facilidade a qualidade dos dados com a dispersão dos valores medidos, e, assim, controlar seu comportamento por meio de um estímulo auxiliar interno: a dispersão dos dados.

Tabela 2 - Erros nas tarefas 1 (processamento) e 2 (qualidade).

\begin{tabular}{|c|c|c|c|}
\hline \multirow{2}{*}{ Turma } & \multirow{2}{*}{$\begin{array}{l}\text { Número de } \\
\text { indivíduos }\end{array}$} & \multicolumn{2}{|c|}{ Erros (\%) } \\
\hline & & Tarefa 1 & Tarefa 2 \\
\hline I & 42 & $11(26)$ & 8 (19) \\
\hline III & 13 & $2(15)$ & $0(0)$ \\
\hline
\end{tabular}

Dentre esses estudantes, selecionamos um exemplo (EI8) que inclusive deixa explícito que signo utilizou na atribuição de qualidade: “Os resultados serão comparados através da precisão dos resultados de cada grupo. Como os valores obtidos pelo grupo A estão mais próximos da média do que os valores obtidos pelo grupo $B$, o resultados do grupo A são mais precisos e, portanto, melhores". Contudo, alguns poucos indivíduos não usaram o signo científico adequado conforme ilustra a resposta de EI1 a seguir: "Já que as médias de ambos os grupos são iguais, não é possível mensurar superioridade de uma medida em relação a outra. Os resultados do grupo A são tão bons quanto os do grupo B". A aparente redução do número relativo de erros da turma III com relação à turma I e a qualidade das respostas escritas indicam apenas que a dispersão, embora ausente no texto do questionário, passa a desempenhar cada vez mais o papel de estímulo indireto. O teste estatístico, no entanto, não permite estabelecer essa redução como significativa com os dados disponíveis.

Nas Tabelas 3, 4 e 5 estão os erros em relação ao total de indivíduos de cada turma para duas tarefas relacionadas, assim como a diferença entre os erros relativos. Na tabela 3 são encontrados os erros relativos para as tarefas 3 e 5 que envolvem a comparação de dados de dois grupos A e B. Observando os dados da tarefa 3, vemos que os erros relativos diminuem da turma I para a turma III $(\mathrm{p}=0,02)$. Para a tarefa 5 , não é possível afirmar com base estatística diferença no número de erros relativos entre as duas turmas. A redução entre os erros relativos das tarefas 3 e 5 é evidente para as duas turmas $(\mathrm{p}<0,005)$, sendo esta diferença menor para a turma III.

\footnotetext{
${ }^{9}$ O teste estatístico de Fisher-Boschloo com nível de significância de 5\% foi utilizado para verificar compatibilidade ou sinalizar redução na taxa de erro tanto entre tarefas relacionadas para uma mesma turma quanto entre turmas numa mesma tarefa. O modelo empregado é o binomial (LYDERSEN et al. 2009).
} 
Para ilustrar como aparecem contrastes nas justificativas de tarefas relacionadas citamos os textos de dois estudantes da turma III. O estudante EIII6 escreveu na tarefa 3, "Sim. Porque as médias com suas devidas incertezas sendo consideradas, os valores concordam entre si", e na tarefa 5, "Sim. Pois se considerarmos o valor do grupo A + sua incerteza e o valor do grupo B menos a sua incerteza, os resultados são condizentes", o que mostra um raciocínio que fez uso de intervalo de confiança e independente do estímulo externo. Por outro lado, confrontando as respostas escritas dadas pelo estudante EIII12 na tarefa 3, "Não. As médias possuem uma grande diferença", e na tarefa 5, "Sim. Pois levando em consideração as incertezas dos dois valores, eles irão apresentar o mesmo valor e alguns valores estarão dentro dos intervalos", fica evidente a influência exercida pelo estímulo externo.

Tabela 3 - Erros nas tarefas de comparação 3 e 5.

\begin{tabular}{|c|c|c|c|c|}
\hline \multirow{2}{*}{ Turma } & \multirow{2}{*}{$\begin{array}{l}\text { Número } \\
\text { de indiví- } \\
\text { duos }\end{array}$} & \multicolumn{2}{|c|}{$\operatorname{Erros}(\%)$} & \multirow{2}{*}{$\begin{array}{c}\text { Diferen- } \\
\text { ça }(\%)\end{array}$} \\
\hline & & Tarefa 3 & Tarefa 5 & \\
\hline I & 42 & $36(86)$ & $1(2)$ & $35(83)$ \\
\hline III & 13 & $7(54)$ & $0(0)$ & $7(54)$ \\
\hline
\end{tabular}

A tabela 4 contém os dados das tarefas 3 e 7 cuja finalidade também era comparar os conjuntos de dados de dois grupos A e B. Aqui uma análise cuidadosa mostra que os dados apresentados no texto da tarefa 7 não são compatíveis. É observado comportamento semelhante ao da comparação das tarefas 3 e 5, com erros e diferenças muito parecidos. Na tarefa 7, não é observada variação significativa entre as duas turmas. A redução entre os erros relativos das tarefas 3 e 7 também é evidente para as duas turmas $(\mathrm{p}<0,03)$, sendo a diferença menor para a turma III.

Tabela 4 - Erros nas tarefas de comparação 3 e 7.

\begin{tabular}{ccccc}
\hline Turma & $\begin{array}{c}\text { Número } \\
\text { de indiví- } \\
\text { duos }\end{array}$ & \multicolumn{2}{c}{ Erros $(\%)$} & $\begin{array}{c}\text { Diferen- } \\
\text { ça }(\%)\end{array}$ \\
\hline I & 42 & $36(86)$ & $0(0)$ & $36(86)$ \\
III & 13 & $7(54)$ & $1(8)$ & $6(46)$ \\
\hline
\end{tabular}

O contraste entre as turmas I e III apresentado acima envolve principalmente tarefas de comparação entre conjuntos de dados ${ }^{10}$. Alguns estudantes da turma I demonstram indícios

\footnotetext{
${ }^{10} \mathrm{Na}$ realidade a tarefa 3, por apresentar somente os dados experimentais e o valor médio destes, na pré-tarefa os estudantes que usaram o signo adequado tiveram que estimar de alguma forma a dispersão dos dados.
} 
de uso da noção de intervalo de confiança porque o nosso material de pesquisa foi coletado com cerca de metade do primeiro curso de laboratório já completado. Observações comuns em sala de aula por parte de qualquer professor e as pesquisas de ensino em medição confirmam que se a nossa coleta houvesse sido realizada logo após o início do semestre, os erros relativos da turma I seriam consideravelmente maiores nessas tarefas, assim como a discrepância entre esses resultados e aqueles da turma mais adiantada.

A Tabela 5 contém os dados relativos às tarefas 4 e 6 que avaliam a capacidade dos estudantes relatarem corretamente um resultado obtido após agruparem o conjunto de dados do grupo A com o conjunto do grupo B. Nota-se uma redução de erros aparente da tarefa 4 para a tarefa 6 para a turma I. Devido ao número limitado de alunos na turma III não é possível estabelecer uma tendência. Na tarefa 4 o número relativo de erros é menor para turma III do que para a turma I ( $\mathrm{p}=0,02)$, enquanto que para a tarefa 6 não é possível excluir a compatibilidade do número relativo de erros entre as duas turmas apesar da diferença aparente nos dados.

Tabela 5 - Erros nas tarefas de processamento 4 e 6.

\begin{tabular}{ccccc}
\hline \multirow{2}{*}{ Turma } & \multirow{2}{*}{$\begin{array}{c}\text { Número de } \\
\text { indivíduos }\end{array}$} & \multicolumn{2}{c}{ Erros $(\%)$} & Diferença \\
\cline { 3 - 4 } & Tarefa 4 & Tarefa 6 & $(\%)$ \\
\hline I & 42 & $24(57)$ & $17(40)$ & $7(17)$ \\
III & 13 & $3(23)$ & $3(23)$ & $0(0)$ \\
\hline
\end{tabular}

Dentre as respostas dadas por estudantes da turma I, EI11 escreveu na tarefa 4, "Os dois grupos devem relatar a média entre todos os valores obtidos pelos grupos", e na tarefa 6, "Eles devem relatar uma média dos valores centrais e sua respectiva incerteza", evidenciando a necessidade de um estímulo auxiliar para completar a tarefa.

A discussão de nossos resultados, em especial aqueles contidos nas tabelas 3 e 4 , indica a influência exercida pela incerteza colocada como estímulo externo no texto, dado que são observadas alterações significativas considerando o teste estatístico de Fisher-Boschloo. Em tarefas de comparação de conjuntos de dados, seja da tarefa 3 para a tarefa 5 ou da tarefa 3 para a tarefa 7, o desempenho de ambas as turmas foi aprimorada. No que diz respeito à tarefa 3, em que não há estímulo externo, a comparação entre turmas mostra uma diferença significativa, um indicativo de que para tarefas de comparação de medições os estudantes da turma III podem estar utilizando com mais frequência a incerteza como um estímulo interno. Sugere também que grande parte dos estudantes da turma I ainda não completou a reconstrução interna do estímulo externo visto que a incerteza é o signo necessário para realizar a mediação na análise de comparações entre medições.

Por outro lado, os resultados apresentados nas tabelas 2 e 5, onde estão envolvidas tarefas de processamento e apresentação ou avaliação da precisão, não sugerem alterações 
significativas tais como as observadas para as tarefas do parágrafo anterior. Nas tarefas espontâneas 1 e 2 são observados desempenhos razoáveis das duas turmas, com número de erros relativos baixos, enquanto que na tarefa 3 são observados baixos aproveitamentos no emprego da incerteza por ambas as turmas e na tarefa 4 o aproveitamento da turma I também é baixo enquanto se observa um desempenho melhor na turma 3 apenas. As tarefas 1 e 2 indicam alguma associação que vincula uma incerteza a uma medição, seja no ato de relatar ou avaliar a precisão, e as tarefas 3 e 4 indicam a efetiva utilização da incerteza como um instrumento abstrato e necessário no ato de comparar, processar e relatar os dados de uma medição. Dessa forma, a comparação do desempenho entre estes dois tipos de questões para cada turma pode ser utilizado para se avaliar de forma qualitativa a utilização do estímulo interno pelos alunos.

Tabela 6 - Diferença percentual entre erros relativos das tarefas 1 e 2 com as 3 e 4 .

\begin{tabular}{ccccc}
\hline \multirow{2}{*}{ Turma } & \multicolumn{4}{c}{ Tarefas } \\
& 1,3 & 2,3 & 1,4 & 2,4 \\
\hline I & 59,5 & 66,7 & 30,9 & 38,1 \\
III & 38,4 & 53,8 & 7,7 & 23,0 \\
\hline
\end{tabular}

Na tabela 6 são apresentadas as diferenças relativas para comparação entre as tarefas sem estímulo externo para cada turma em separado. Na turma I são constatadas alterações evidentes em todas as combinações pertinentes, e revela que o vínculo associativo criado entre medição e incerteza não determina o emprego correto da incerteza de forma voluntária. Nessa mesma análise, a turma III apresenta diferenças nos erros relativos menores que para a turma I, o que assinala um emprego mais adequado da incerteza como mediador na análise de dados de grandezas físicas. Para a turma I, o teste estatístico para cada par da tabela 6 rejeita a hipótese de compatibilidade entre o número de erros relativos entre as tarefas de cada par indicando que as diferenças são significativas. $O$ mesmo ocorre para os pares de tarefa 1, 3 e 2, 3 da turma III cujas diferenças são significativas, enquanto isso não pode ser afirmado para os pares 1,4 e 2,4 da mesma turma. No entanto, as diferenças dos pares 1, 4 e 2, 4 são pequenas e demonstram novamente uso mais adequado das incertezas na análise de dados de grandezas físicas, pois os erros percentuais absolutos são baixos nas três tarefas.

\section{Considerações finais}

Analisamos a organização do pensamento abstrato com que estudantes completam tarefas típicas no laboratório de física na universidade sobre uma experiência hipotética. Nossa investigação se concentrou no uso voluntário e sistemático da incerteza por estudantes universitários em tarefas de um contexto experimental específico, e por isso não avaliamos a utilização da incerteza de forma arbitrária, isto é, no tratamento de dados obtidos a partir de ou- 
tras situações experimentais (como, por exemplo, medidas repetidas de tempo), e nem em outras tarefas típicas de laboratório (como a realização de um ajuste linear, por exemplo). Adotamos um levantamento escrito compacto (KUNG; LINDER, 2006) e interpretamos as respostas dadas por estudantes em termos de percepção e de pensamento mediados por signos usando o referencial teórico de Vigotski, uma avaliação distinta da descrição pormenorizada de outros autores (ALLIE et al.; CAMPBELL et al, 2005) em termos de categorias intermediárias entre os paradigmas de ponto e de conjunto.

Nossa análise consistiu em confrontar pares de tarefas relacionadas, tal que em apenas uma destas um estímulo externo estava presente no texto, ou pares em que não havia qualquer estímulo. Na primeira situação foram encontradas alterações estatisticamente significativas em tarefas de comparação de medidas (Tabelas 3 e 4) para uma mesma turma, e também quando confrontamos o desempenho das duas turmas na tarefa de comparação sem estímulo. Em tarefas de processamento de dados seguida da apresentação da medida (Tabela 5), embora não tenha sido observada variação significativa no desempenho da turma III, houve redução significativa para a turma I assim como entre as duas turmas na tarefa sem estímulo. Na situação em que se confronta o uso voluntário da incerteza (Tabela 6), para a turma I observamos alterações significativas em todas as combinações, enquanto que para a turma III apenas para combinações com as tarefas de comparação de medidas. As alterações estatisticamente significativas no desempenho de cada turma nos sugere uma forte influência exercida na mediação do pensamento abstrato pelos estímulos artificiais colocados à disposição dos estudantes, e as reduções significativas encontradas entre turmas sugerem que os estudantes da turma mais avançada necessitam menos de estímulos externos que os estudantes da turma I.

As dificuldades encontradas pelos estudantes não se restringem apenas ao tratamento de dados abstrato com a incerteza. A simples observação por parte de nossos estudantes de que outros grupos de alunos hipotéticos relataram seus resultados com um intervalo de valores foi capaz de modificar consideravelmente o signo empregado no pensamento abstrato subsequente, algo que podemos compreender em termos de regulação exterior (VIGOTSKI, 2007; WERTSCH, 1985), esta entendida como regulação tanto da percepção quanto do processamento dos dados. Neste sentido, ainda que a estratégia inicialmente escolhida para completar uma tarefa no laboratório de física seja a de um grupo hipotético de indivíduos, vemos que a incerteza surge primeiro no plano interpsicológico para em seguida ser utilizada no plano intrapsicológico. Assim, atividades experimentais orientadas a interações sociais (LABURÚ et al., 2010; WERLANG, 2012; CARVALHO, 2013) assumem uma posição importante para permitir que os estudantes superem as dificuldades com o método científico.

\section{Referências}

ALLIE, S. et al. First-year physics students' perceptions of the quality of experimental measurements. International Journal of Science Education, v. 20, n. 4, p. 447-459, 1998. 
BUFFLER, A.; ALLIE, S.; LUBBEN, F. The development of first year physics students' ideas about measurement in terms of point and set paradigms. International Journal of Science Education, v. 23, n. 11, p. 1137-1156, 2001.

CAMPBELL, B. et al. Teaching Scientific Measurement at University: Understanding Students' Ideas and Laboratory Curriculum Reform. Kloof: SAARMSTE, 2005.

CARVALHO, A. M. P. (Org.). Ensino de ciências por investigação: condições para implementação em sala de aula. São Paulo: Cengage Learning, 2013.

HOWE, A. C. Development of Science Concepts within a Vygotskian Framework. Science Education, v. 80, n. 1, p. 35-51, 1996.

JOINT COMMITEE FOR GUIDES IN METROLOGY. Evaluation of Measurement Data: Guide to the Expression of Uncertainty in Measurement. Sèvres, 2008. Disponível em: <http://www.bipm.org/en/publications/guides>. Acesso em: 4 jan. 2016.

KUNG, R. L.; LINDER, C. University students' ideas about data processing and data comparison in a physics laboratory course. Nordic Studies in Science Education, v. 4, p. 40-53, 2006.

LABURÚ, C. E.; BARROS, M. A. Problemas com a compreensão de estudantes em medição: razões para a formação do paradigma pontual. Investigações em Ensino de Ciências, v. 14, n. 2, p. 151-162, 2009.

LABURÚ, C. E.; SILVA, O. H. M.; SALES, D. R. Superações conceituais de estudantes do ensino médio em medição a partir de questionamentos de uma situação experimental problemática. Revista Brasileira de Ensino de Física, v. 32, n. 1, p. 1402-1415, 2010.

LYDERSEN, S.; FAGERLAND, M. W.; LAAKE, P. Recommended tests for association in 2x2 tables. Statistics in Medicine, v. 28, n. 7, p. 1159-1175, 2009.

LURIA, A. R. A construção da mente. 2. ed. São Paulo: Ícone, 2015, 240 p.

A psicologia experimental e o desenvolvimento infantil. In: VIGOTSKII, L. S.; LURIA, A. R.; LEONTIEV, A. N. Linguagem, Desenvolvimento e Aprendizagem. 12. ed. São Paulo: Ícone, 2014, p. 85-102.

. Desenvolvimento cognitivo. 6. ed. São Paulo: Ícone, 2013.

Vigotskii. In: VIGOTSKII, L. S.; LURIA, A. R.; LEONTIEV, A. N. Linguagem, Desenvolvimento e Aprendizagem. 12. ed. São Paulo: Ícone, 2014, p. 21-37.

MARINELI, F.; PACCA, J. L. A. Uma interpretação para dificuldades enfrentadas pelos estudantes em um laboratório didático de Física. Revista Brasileira de Ensino de Física, v. 28, n. 4, p. 497-505, 2006. 
PEREIRA, A. P.; JUNIOR, P. L. Implicações da perspectiva de Wertsch para a interpretação da teoria de Vygotsky no ensino de Física. Caderno Brasileiro de Ensino de Física, v. 31, n. 3 , p. 518-535, 2014.

PIAGET, J. Epistemologia genética. 4. ed. São Paulo: Wmf Martins Fontes, 2012.

VIGOTSKI, L. S. A construção do pensamento e da linguagem. 2. ed. São Paulo: Martins Fontes, 2009.

A Formação social da mente: $\mathrm{O}$ desenvolvimento dos processos psicológicos superiores. 7. ed. São Paulo: Martins Fontes, 2007.

WERLANG, R. B. et al. Análise da inserção da teoria sociointeracionista em atividades de laboratório de física básica em um curso de geofísica, Caderno Brasileiro de Ensino de Física, v. 29, n. 2, p. 246-266, 2012.

WERTSCH, J. V. Vygotsky and the Social Formation of Mind. Cambridge: Harvard University Press, 1985.

VUOLO, J. H. Avaliação e expressão de incerteza em medição. Revista Brasileira de Ensino de Física, v. 21, n. 3, p. 350-358, 1999. 